Rhode Island College

Digital Commons @ RIC

$5-1-2013$

\title{
Online Learning Modules and Nursing Students' Knowledge of Tuberculosis
}

Monica L. Kunkel

Rhode Island College

Follow this and additional works at: https://digitalcommons.ric.edu/etd

Part of the Nursing Commons

\section{Recommended Citation}

Kunkel, Monica L., "Online Learning Modules and Nursing Students' Knowledge of Tuberculosis" (2013). Master's Theses, Dissertations, Graduate Research and Major Papers Overview. 219.

https://digitalcommons.ric.edu/etd/219

This Major Paper is brought to you for free and open access by the Master's Theses, Dissertations, Graduate Research and Major Papers at Digital Commons @ RIC. It has been accepted for inclusion in Master's Theses, Dissertations, Graduate Research and Major Papers Overview by an authorized administrator of Digital Commons @ RIC. For more information, please contact digitalcommons@ric.edu. 


\section{ONLINE LEARNING MODULES}

\section{AND NURSING STUDENTS' KNOWLEDGE OF TUBERCULOSIS}

by

Monica L. Kunkel

A Major Paper Submitted in Partial Fulfillment

Of the Requirements for the Degree of

Master of Science in Nursing

in

The School of Nursing

Rhode Island College

2013 


\begin{abstract}
Tuberculosis is identified as a major global health issue. Recommendations for increased training for health professionals from both the Institute of Medicine and the National Institutes of Health have been outlined. Nursing curriculum tools developed by the National Tuberculosis Consortium and presented through online learning modules were utilized in an experimental study of baccalaureate nursing students. Knowles' Theory of Adult Learning provided the theoretical framework for the study. The test scores on a thirty question multiple-choice exam of students who participated in the intervention are compared to those of students who only participated in the regular course content. Although the mean raw score on the exam was higher for the experimental than the control group, the small number of participants that completed the study prevented the results from being analyzed to determine if there was a statistically significant difference between the two groups. Limitations of the study included the small sample size, inexperience of the investigator in designing and conducting an experimental study, the amount of extra time involved for students in the intervention group, and the lack of ability to correlate demographic information to individual results. Implications for nurses prepared to practice at the master's level include the need for further research to explore effective teaching methods for baccalaureate nursing students; involvement in policy development related to tuberculosis knowledge and screening, especially of health care workers; and a recommendation for a continued commitment to encourage nurse research on educating future nurses on complex heath care topics such as tuberculosis.
\end{abstract}


Table of Contents

Table of Contents..................................................

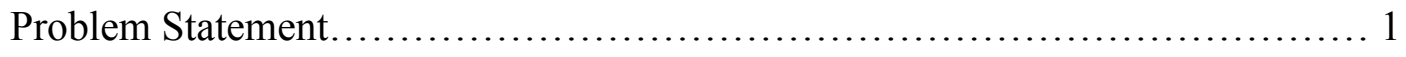

Literature Review........................................................5

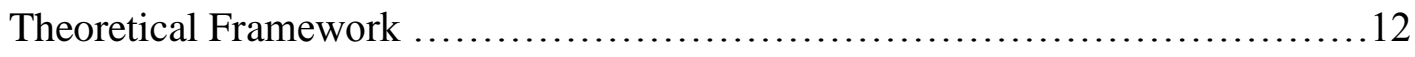

Method.................................................................. 13

Results............................................................. 18

Summary and Conclusions............................................. 32

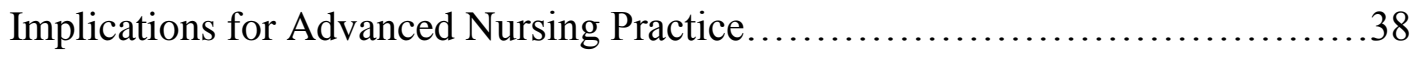

References....................................................... 42

Appendices...........................................................47 


\section{Online Learning Modules and Nursing Students' Knowledge of Tuberculosis}

Tuberculosis (TB) is the second leading cause of death from infectious disease in the world after human immunodeficiency virus/acquired immunodeficiency syndrome (HIV/AIDS). TB is treatable and curable, yet it remains a significant public health threat. According to the World Health Organization, one third of the world's population is infected with the TB bacteria. In 2010, 8.4 million people around the world developed active TB, and 1.4 million people died of the disease (WHO, 2012). In the United States, active cases of TB have been declining over the past two decades, but the incidence among foreign-born residents of the U.S. is ten times higher than those born in the U.S. (Centers for Disease Control, 2012). Socio-economic factors have as much effect on the development of TB as the bacterium that causes it. The complex relationship between TB and issues such as poverty, HIV, homelessness, race, alcoholism, immigration and access to health care have contributed to the persistence of the disease. Inadequate or incomplete treatment of both latent and active TB has contributed to the development of multiple drug resistant (MDR) strains, further complicating efforts to eradicate the disease.

Development of antibiotics in the 1940s was heralded as the beginning of the end of TB in the United States. Case rates began to fall dramatically over the ensuing decades, and in the early 1980s, as a result of the elimination of federal funding, public health departments across the country began dismantling their TB prevention and treatment programs. In New York City in 1978, funding for TB prevention programs 
was half what had been spent five years earlier. Subsequently the next year, the rate of TB in New York City increased for the first time in decades (Brudney \& Dobkin, 1991). Other states and cities also cut funding, and the end result of these measures was a subsequent increase in the number of cases of TB from 1985 to 1992. Factors such as the epidemic of HIV/AIDS, as well as the emergence of multi-drug resistant strains of TB assured that the fight against TB was far from over. Since 1993, renewed efforts and funding have one again contributed to a decline in the number of active TB cases in the U.S. However, since 2003 the speed of decline has slowed. In 2011, a total of 10,521 new TB cases were reported in the United States, an incidence of 3.4 cases per 100,000, which is $6.4 \%$ lower than the rate in 2010 . The percentage decline is greater than the average $3.8 \%$ decline per year observed from 2000 to 2008 but not as large as the record decline of $11.4 \%$ from 2008 to 2009 (CDC, 2012).

The Institute of Medicine (2000) issued a report called "Ending Neglect: The Elimination of Tuberculosis in the United States," stating that the U.S. has a rare "second chance" at finally eliminating TB, after the failure of the 1980s. The IOM report outlined several overarching strategies for tuberculosis elimination, including: (1) finding and curing all persons with active TB; (2) accelerating the decline of TB by treating high risk persons with latent TB infections before they become sick; (3) developing new tools such as vaccines, diagnostic tests and shorter courses of treatment and (4) increased involvement by the United States in the global control of the disease. The Institute also recommended increasing education for health care providers related to TB. In response, 
the National Institutes of Health, in 2003, funded the development of the National Tuberculosis Curriculum Consortium (NTCC), a multidisciplinary effort to strengthen the teaching of content related to TB to health professions students. Core competencies for each category of student (i.e. medical, respiratory therapy, clinical laboratory science, pharmacy, advanced practice nurse, and baccalaureate nurse) were developed (Fair et al., 2006; Harrity, Jackson, Hoffman, \& Catanzaro, 2007), as well as interactive online modules and assessment tools.

In a white paper released in June 2010, NTCC outlined how the materials developed by the consortium can be used with permission and at no charge for learning and teaching about TB. The NTCC competencies are organized across cognitive, psychomotor and attitudinal domains. The American Association of Colleges of Nursing (AACN) endorsed the core competencies developed by the NTCC for baccalaureate nursing programs (Fair et al., 2006).

The NTCC learning tools help students achieve these competencies utilizing online learning modules; a multimedia bank of images, video, and PowerPoint presentations; a question and answer bank; clinical scenarios; and reference materials that include a glossary, bibliography, and TB drug reference. The online learning modules are case based learning exercises. They are peer-reviewed simulations that promote selfpaced learning. When the cases are run by the student using an active internet connection, the question boxes allow open ended responses; once the student types in a free form answer, they can open a dialogue box that gives them the opportunity to see the 
expert opinion, allowing them to compare their response to the correct one. The question and answer bank can be used for self-testing or to develop multiple-choice quizzes.

The online modules can be sorted by health discipline as well. A discipline, in this case baccalaureate nursing, is entered as a parameter, and only the modules with the most relevance to nursing content and competencies are displayed. This experimental study evaluated if the addition of the NTCC developed online learning modules to a baccalaureate nursing curriculum had a significant effect on students' knowledge about tuberculosis. 


\section{Literature Review}

Tuberculosis (TB) remains a major public health challenge in the United States today. Relevant epidemiological data is plentiful and informative. Khan, et al. (2007) tracked the national trends in occurrence of TB infection in the United States over three decades from 1971 to 2000 . Their findings indicated a significant overall decline in the diagnosis of TB in the U.S. since the 1970s, however the prevalence in foreign-born persons was over eight times greater than in U.S. born persons. Bennett, et al. (2008) looked at the prevalence of latent tuberculosis infection (LTBI) and found that over 11 million people in the United States have been identified as infected with TB, but only $13.2 \%$ of them had been prescribed treatment. A study of racial and ethnic health disparities in the U.S. based on Healthy People 2010 objectives revealed that new cases of TB per 100,000 ranked seventh among health disparities for Hispanic, Black nonHispanic, American Indian or Alaska Native, and Asian populations in the U.S. (Keppel, 2007). The development of multidrug resistant (MDR-TB) and extensively drug resistant TB (XDR-TB) is also an emerging problem; treatment of MDR-TB is more expensive and takes longer than the treatment of the traditional disease. The emergence of XDRTB raises the possibility of the development of strains with resistance to all known drugs (Shah, et al., 2008).

\section{Health Professions Students' Tuberculosis Knowledge}

A literature search using the keywords tuberculosis, nursing education and curriculum was conducted on Pub Med, Ovid, Google Scholar and the Cumulative Index 
of Nursing Health Literature, with a limitation of publication since 2005. When it was discerned that very little research on the inclusion of TB in courses for nursing education has been published, the search term health professions students was added.

Many health professions students lack knowledge of TB. Jackson, Harrity, Hoffman, \& Catanzaro (2007) used a survey to assess the knowledge, attitudes, and confidence of students in the health professions, related to the care of patients with TB. The plan of the study was to survey students enrolled in NTCC schools prior to the NTCC materials being made available to faculty. Fifty percent of students completed the pre-intervention survey. Even though almost $90 \%$ of the respondents had attended at least one lecture during which TB was a primary focus, and $56.3 \%$ had attended three or more hours of TB instruction, the results showed the need for improvement in all areas. The major teaching modalities were lectures and case discussion at conferences. The results of this study supported the need for NTCC educational products by demonstrating considerable room for educational improvement. Almost $10 \%$ of students did not know that respiratory droplets transmitted TB, and about one third did not know the correct method for administering a tuberculin skin test or that Bacillus Calmette-Guerin (BCG) vaccine was not a contraindication to TB skin testing.

NTCC faculty were planning to integrate NTCC developed materials into their curricula for the 2007 and 2008 academic years, with plans to re-survey students after the intervention was complete. However, no evidence was found in the literature that any assessment of the effectiveness of the NTCC materials had been published. 
Benkert, et al. (2009) used a 48-item questionnaire similar to Jackson's study (2007) to assess Nurse Practitioner (NP) students' beliefs, knowledge and perceived selfefficacy for TB care. It was distributed to a total of $92 \mathrm{NP}$ students from four universities; the average response rate was $42 \%$. While the study was limited by the small self-selected sample size, results related to TB knowledge showed that the average percent of correct answers was 56\%. The results indicated that NP students were moderately knowledgeable of core TB content and had a moderate level of perceived self-efficacy for care of patients with TB. They also held a moderately high value for TB education. The authors noted that $43 \%$ of the participants had never cared for patients with TB.

Using the same survey as Jackson et al. (2007), Akin et al. (2011) conducted a study of knowledge and attitudes toward TB of Turkish nursing and midwifery students. The findings indicated that the level of TB knowledge was poor, and student attitudes about the disease of TB were generally negative. Students who received education about TB had higher levels of knowledge and more positive attitudes about caring for patients with TB than those who had not received TB education.

Hinski, Goodfellow, Bryant \& Zimmerman (2011) used the same survey prior to and following TB education in a baccalaureate program in respiratory therapy (RT). Forty first-year RT students completed the pre-test and thirty-five of these completed the post-test. The average scores for TB knowledge prior to TB education were $44.5 \%$. After the TB educational intervention, the average improved to $72.4 \%$. Results indicated 
that the students' overall level of knowledge and confidence regarding the treatment of TB increased. The authors recommended further research to determine the most effective parts of the educational content.

\section{Curricular Models of Tuberculosis Education}

Very little research has been published on how to incorporate TB content into nursing education. What was found is that several nursing programs have taken a service learning approach to exposing students to TB content; this involves combining formal learning with a period of related service within a community. Schoener and Hopkins (2004) had students set up a TB screening clinic in an adult residential facility, while Lashley (2007) led students on a professional service learning experience in a faith-based inner city homeless shelter. Belcher, et al. (2011) established a service learning partnership between a local health department and baccalaureate-nursing students that resulted in the development of a latent tuberculosis infection (LTBI) follow-up program that made contacts with 193 patients. Stone (2001) described the addition of a Basic TB Skin Test Course to the baccalaureate curriculum. After completing the didactic TB content, students could elect to receive certification in planting, reading and recording Mantoux tuberculin skin tests. Evaluations by students recommended that the course be continued, with $100 \%$ of students indicating that the course objectives were met. These studies outline practical ways to incorporate TB content into nursing curricula, but none of them measured students' knowledge of TB before or after the service learning activity. 


\section{Effectiveness of Tuberculosis Education}

Some researchers have attempted to measure the effectiveness of education

focused on the topic of TB. In 1998, Moore used a stratified random sampling technique to query 500 nursing education program administrators regarding skin test policies for students, amount of time devoted to TB education, when in the curriculum the content was taught, and the type of material taught. Of the $341(68.2 \%)$ programs that responded, more than $50 \%$ spent less than three classroom hours on TB content. Their reports also indicated there was a gap in knowledge related to multi-drug resistant TB and the difference between pulmonary and extra-pulmonary TB. A recommendation was made by the researchers to increase the curriculum time devoted to TB to six hours. The applicability of this study, reported 15 years ago, is limited by its age, however curriculum concerns are still valid, as evidenced by Jackson et al.'s (2007) findings that over $75 \%$ of health profession students had less than four hours of TB specific instruction.

An educational research survey sent to Brazilian nursing school administrators in 2004 (Villa et al., 2006) showed that there had been little change in the way TB content had been taught since the previous survey in 1976, 28 years earlier. The researchers' recommendation, published in 2006, was that teaching on TB should move beyond the traditional model that only focuses on the biological aspects of the disease. In addition they stated that TB education should utilize tools that lead to behavioral change, and deal with the public health aspects of the disease, with an emphasis on experiential learning. 


\section{Experiential Learning}

One of the ways experiential learning is achieved is through the use of internetbased learning, such as that employed by the online modules developed by the NTCC. A meta-analysis of internet-based learning in the health professions (Cook, et al. 2008) compared the effect of internet-based instruction for health professions learners with no intervention and with non-internet intervention. Reviewing the 201 studies that met the inclusion criteria showed that internet-based learning is associated with large positive effects when compared with no intervention. The effects of internet-based learning and traditional methods of instruction, when compared, were found to be similar.

Case studies were determined to be an effective way to present material in a medical-surgical nursing course. DeSanto-Madeya (2007) used a case study approach over two semesters, based on the Roy Adaptation Model. Course evaluations and informal surveys revealed that the students stated that they had benefited. Students commented about the time required to complete the weekly case studies, but stated that their critical thinking skills were enhanced by this active learning process.

In a review of over one thousand online learning studies from 1996 to 2008, Means, Toyama, Murphy, Bahia \& Jones (2010) identified fifty independent effects that could be subject to meta-analysis. The meta-analysis found that, on average, students in online learning conditions performed modestly better than those receiving face-to-face instruction. The difference between student outcomes for online and face-to-face classes - measured as the difference between treatment and control means, divided by the 
pooled standard deviation — was larger in those studies contrasting conditions that blended elements of online and face-to-face instruction with conditions taught entirely face-to-face. Analysts noted that these blended conditions often included additional learning time and instructional elements not received by students receiving instruction either totally online or totally face-to-face.

Several studies have been done using The Survey of Knowledge and Confidence Related to Tuberculosis developed by the NTCC. This was the survey tool that provided the impetus for the development of educational materials by the Consortium, including the online learning modules created by the National Tuberculosis Curriculum Consortium.

Studies indicating that case studies and internet-based learning can have a positive effect on student outcomes support the use of the experiential based learning modules in a baccalaureate curriculum. To date, there have been no published studies found that evaluate the effectiveness of the NTCC modules on students' knowledge of tuberculosis when incorporated into a baccalaureate nursing curriculum. 


\section{Theoretical Framework}

The theoretical framework for this study is based on Knowles (1970) theory of adult learning. This theory states that teacher-directed learning, or "pedagogy" is really more suited to the teaching of children; self-directed, or adult, learning called "andragogy" assumes that learners are motivated by internal incentives such as the satisfaction of accomplishment, the urge to grow, and curiosity. As his theory continued to evolve, Knowles later acknowledged that the theory was not really defined by the age of the learner, but by the willingness or ability of the learner to develop knowledge independently.

In 1975, Knowles further refined the theory of self-directed learning, stating "a basic human competence is the ability to learn on one's own" (p. 17). This theory proposes that people who take the initiative in learning (pro-active learners) enter into learning more purposefully and with greater motivation than those who passively wait to be taught by teachers (reactive learners). According to Knowles, self-directed learners learn more things and learn better than reactive learners. Knowles also postulated that self-directed learning is more in tune with our natural processes of psychological development. These learners also tend to retain and make use of what they learn. 


\section{Method}

The purpose of the study was to determine the effect of the completion of online learning modules developed by the National Tuberculosis Curriculum Consortium (NTCC) on baccalaureate-nursing students' overall knowledge of tuberculosis (TB). The design of the study was experimental.

\section{Site and Sample}

The study took place at Rhode Island College (RIC) in Providence, RI. The college's Institutional Review Board determined the study was exempt from review. The

investigator recruited third year baccalaureate nursing students enrolled in two sections of Adult Health Nursing I in the Fall 2012 semester to participate in the study. This course was chosen for the study because the main components of TB education in the baccalaureate curriculum are included in the respiratory content covered in weeks 10 to 13 of the 15 -week semester.

There were no exclusion criteria; any student from the two course sections, who was willing, and signed the consent form, was allowed to participate. The total enrollment for both sections was 47 students and the goal was to recruit 30 students.

\section{Procedure}

The investigator received permission from the professor teaching the course to speak to each section, provide students with information about the study and ask if any student would be willing to participate. The investigator was given approximately 10 minutes of class time in week 8 of the semester to explain the study to the students, and 
then distributed consent forms (Appendix A) to those students who indicated interest. Students were assured that their choice to participate would have no effect on their grade for the course, and that they could drop out of the study at any time with no consequences. As an incentive, students were told that if they completed the entire study, they would receive a $\$ 10.00$ coffee shop gift card. From the two class sections, a total of 38 students signed consent forms and provided contact information to receive e-mails instructing them on how to participate. Subsequent contacts with the participants were made entirely through e-mail. The initial e-mail contact was made two days after the students were recruited. A questionnaire was sent electronically to the participants using a Google Drive online survey form requesting demographic information concerning age, gender, ethnicity, and whether they were basic or second-degree students (Appendix B). The responses were returned anonymously to the investigator, populating a spreadsheet in the form software.

The students were then alternately assigned to either the control group or experimental group, using every other one randomization. The control group received an e-mail in week 9 of the course informing them that they did not need to take any action at this time (Appendix C). The experimental group received an e-mail in week 9 of the course with instructions on how to register on the NTCC website (Appendix D). They were instructed to forward the registration confirmation to the investigator. Two followup e-mails, sent five days apart, included the instructions again and reminded the members of the experimental group to register. At the end of a two-week period, in week 
11, an additional e-mail was sent to the members of the experimental group who did not register, confirming that this would end their participation in the study (Appendix E). The members of the experimental group who registered were sent instructions in week 12 , at the same time that TB content was beginning to be covered during class, informing each of them which case studies to complete and send back to the investigator (Appendix F). These three case studies were chosen by the researcher because they were classified by NTCC as including content appropriate for baccalaureate nursing students. Each of the three case studies took approximately one hour to complete. Students were given a deadline coinciding with the approximate date that the respiratory content would be completed in Adult Health Nursing I, which was week 13. A reminder e-mail was sent to the experimental group at the beginning of week 13, asking them to complete the case studies prior to the deadline, and letting them know that they would be receiving a link to a multiple choice exam after the TB content had been covered in class. Completed case studies were e-mailed to the investigator through a link at the end of each one that enabled the students to enter the investigator's e-mail address. The control group was also sent an email telling them that they would be receiving a link to the multiple-choice exam after the TB content was completed in class.

The TB content was completed in week 13 of Adult Health Nursing I, and at the beginning of week 14 the students in the experimental group still enrolled in the study and the students in the control group received a thirty question multiple-choice exam developed by the NTCC (Appendix G). The exam format was an online Google Drive 
survey form, and the answers to the questions were submitted and populated in a spreadsheet. Students were asked to provide their names in a free text box at the end of the exam so that it could be determined whether they were members of the experimental or control group. Two reminder e-mails were sent 5 days apart, noting that completion of the exam was a condition for receiving the incentive. At the beginning of the Spring 2013 semester, all students who completed the exam were mailed a $\$ 10.00$ coffee shop gift card for their participation. In an e-mail from the investigator requesting their mailing address, all participants in the control group were given the opportunity to request information on how to access the NTCC website.

\section{Measurement}

Measurement tools included a demographic questionnaire (Appendix B) that was sent to all participants in the study. A thirty question multiple-choice exam developed by NTCC (Appendix G) was completed by participants from the experimental group and the control group. The multiple-choice exam had been built by the investigator from the NTCC website using questions selected specifically for baccalaureate nursing students; the three case studies completed by the experimental group had been selected using the same criteria. A similar tool utilizing selected questions had been used with Nurse Practitioner students (Benkert, et al., 2009) and found to have evidence of reliability and validity. In that study, Rasch's analysis indicated excellent internal consistency with a reliability score of 0.96 for the TB knowledge measures (Benkert, et al., 2009).

For this study the demographic data collected at the outset was analyzed using 
frequencies and percentages. Each multiple-choice exam was scored using raw scores and percentages. Descriptive statistics including mean, standard deviation, median, and range were calculated for the NTCC exam raw scores for both the experimental and control group. Frequencies and percentages of correct answers for individual questions for the experimental and control groups, as well as the total for both groups were calculated. Students were given a free text box at the end of the exam and asked to share any comments they had about the research study, the case studies or TB in general. The use of students in a research study has ethical considerations, due to their classification as a vulnerable group. It was made clear to the potential participants at the time of recruitment that participation in the study, as well as their scores on the multiple choice exam would have no effect on grading for Adult Health Nursing I. 


\section{Results}

Initial enrollment for the study was 38 students. Of those 38 students, 30 responded to the request for demographic information. Demographic characteristics are reported in Figure 1. Traditional baccalaureate students comprised $60 \%$ of the sample, while second-degree students accounted for $37 \%$. The sample was overwhelmingly female (97\%), and the majority (80\%) were between the ages of 18 and 27 . A majority (83\%) identified themselves as Caucasian.

The 38 students who enrolled were randomized to an experimental $(\mathrm{n}=19)$ and control $(n=19)$ group using every other one randomization. Eleven members of the experimental group registered on the NTCC website, and six of them completed all three of the online modules. The six who completed the online modules also completed the multiple-choice exam. Of the control group, fifteen completed the multiple-choice exam, resulting in 21 students who completed the entire study. 

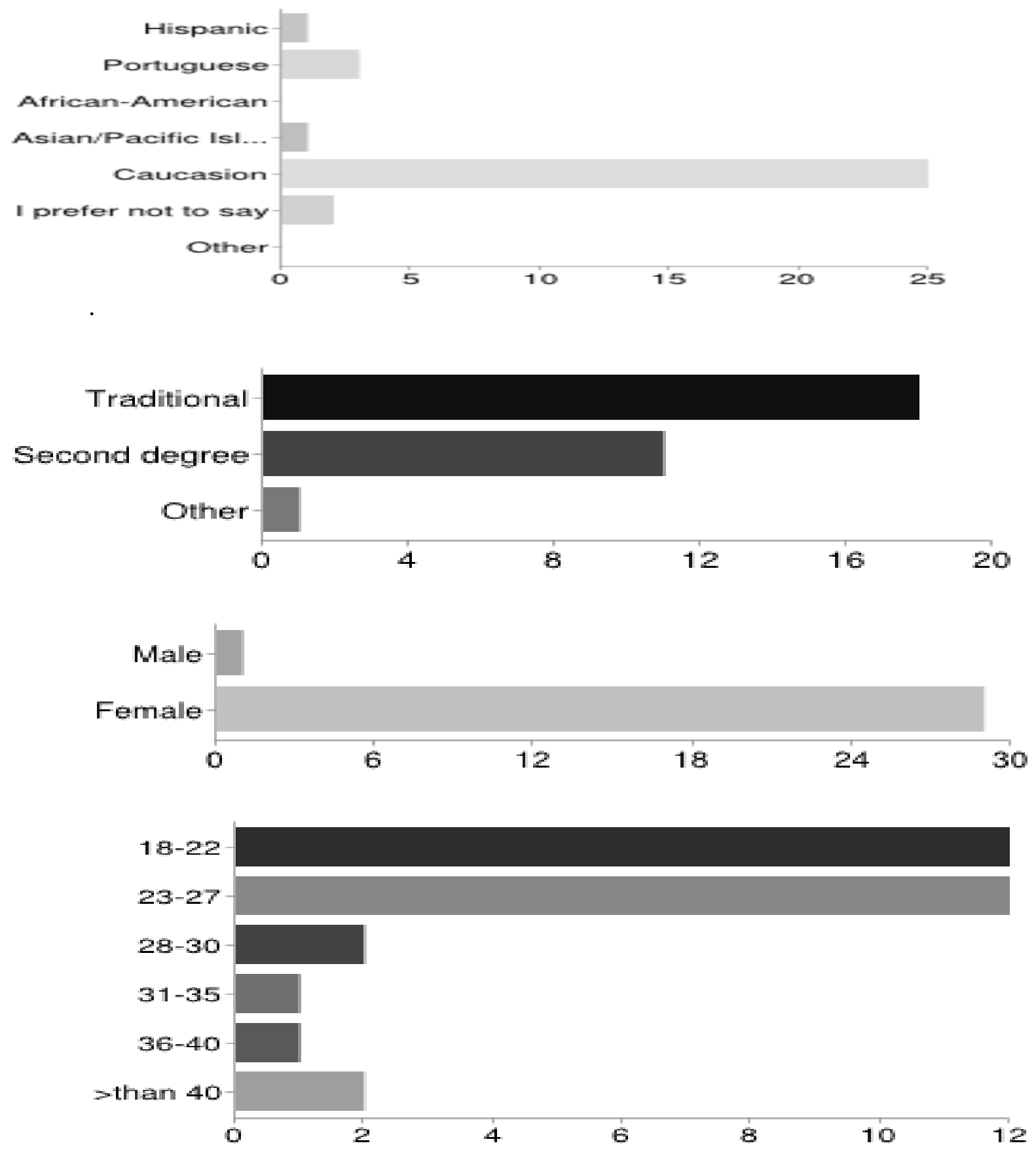

Figure 1. Demographic characteristics of initially enrolled students 
As seen in Table 1, the experimental group mean of scores was higher than the control group, while the median was almost the same. The control group, which had more than twice the number of participants, had a larger standard deviation and a wider range of raw scores in comparison to the experimental group. 
Table 1

Means, Standard Deviations, Medians and Ranges of NTCC Exam Scores for the Experimental and Control Groups

\begin{tabular}{lcccc} 
Group & Mean & $\begin{array}{l}\text { Standard } \\
\text { Deviation }\end{array}$ & Median & Range \\
\hline Experimental $(\mathrm{n}=6)$ & 77.22 & 6.135 & 76.65 & $70.0-86.7$ \\
Control $(\mathrm{n}=15)$ & 73.55 & 9.212 & 76.70 & $63.3-93.3$ \\
\end{tabular}


As seen in Table 2 the percentages of correct answers for each item for both groups combined, ranged from $10 \%$ to $100 \%$. For the experimental group the percentages of correct answers for each item ranged from $0 \%$ to $100 \%$ and for the control group, percentages of correct answers for each item ranged from $7 \%$ to $100 \%$. Comparing the percentages of correct answers for each item, the experimental group had a higher frequency of correct answers for $15(50 \%)$ of the questions, while the control group had a higher frequency of correct answers for $8(27 \%)$ of the questions. There was no difference between the experimental and control groups in the frequency of correct answers for 7 (23\%) questions. 
Table 2

Frequencies and percentages of correct answers for individual questions on the NTCC Exam

\begin{tabular}{|c|c|c|c|c|c|c|}
\hline \multirow[t]{2}{*}{ Question } & \multicolumn{2}{|c|}{ Experimental } & \multicolumn{2}{|c|}{$\underline{\text { Control }}$} & \multicolumn{2}{|l|}{$\underline{\text { Total }}$} \\
\hline & Frequency & $\%$ & Frequency & $\%$ & Frequency & $\%$ \\
\hline 1 & 4 & $67 \%$ & 12 & $80 \%$ & 16 & $76 \%$ \\
\hline 2 & 5 & $83 \%$ & 12 & $80 \%$ & 17 & $81 \%$ \\
\hline 3 & 6 & $100 \%$ & 15 & $100 \%$ & 21 & $100 \%$ \\
\hline 4 & 6 & $100 \%$ & 15 & $100 \%$ & 21 & $100 \%$ \\
\hline 5 & 6 & $100 \%$ & 6 & $40 \%$ & 12 & $57 \%$ \\
\hline 6 & 6 & $100 \%$ & 14 & $93 \%$ & 20 & $95 \%$ \\
\hline 7 & 4 & $67 \%$ & 10 & $67 \%$ & 14 & $67 \%$ \\
\hline 8 & 1 & $17 \%$ & 1 & $7 \%$ & 2 & $10 \%$ \\
\hline 9 & 6 & $100 \%$ & 15 & $100 \%$ & 21 & $100 \%$ \\
\hline 10 & 3 & $50 \%$ & 6 & $40 \%$ & 9 & $43 \%$ \\
\hline 11 & 2 & $33 \%$ & 9 & $60 \%$ & 11 & $52 \%$ \\
\hline 12 & 6 & $100 \%$ & 12 & $80 \%$ & 18 & $86 \%$ \\
\hline 13 & 4 & $67 \%$ & 11 & $73 \%$ & 15 & $71 \%$ \\
\hline 14 & 6 & $100 \%$ & 14 & $93 \%$ & 20 & $95 \%$ \\
\hline 15 & 0 & 0 & 7 & $47 \%$ & 7 & $33 \%$ \\
\hline 16 & 6 & $100 \%$ & 14 & $93 \%$ & 20 & $95 \%$ \\
\hline 17 & 6 & $100 \%$ & 11 & $73 \%$ & 17 & $81 \%$ \\
\hline 18 & 4 & $67 \%$ & 8 & $53 \%$ & 12 & $57 \%$ \\
\hline 19 & 4 & $67 \%$ & 6 & $40 \%$ & 10 & $48 \%$ \\
\hline 20 & 5 & $83 \%$ & 14 & $93 \%$ & 19 & $90 \%$ \\
\hline 21 & 6 & $100 \%$ & 15 & $100 \%$ & 21 & $100 \%$ \\
\hline 22 & 6 & $100 \%$ & 13 & $87 \%$ & 19 & $90 \%$ \\
\hline 23 & 6 & $100 \%$ & 15 & $100 \%$ & 21 & $100 \%$ \\
\hline 24 & 6 & $100 \%$ & 12 & $80 \%$ & 18 & $86 \%$ \\
\hline 25 & 3 & $50 \%$ & 5 & $33 \%$ & 8 & $38 \%$ \\
\hline 26 & 4 & $67 \%$ & 11 & $73 \%$ & 15 & $71 \%$ \\
\hline 27 & 1 & $17 \%$ & 6 & $40 \%$ & 7 & $33 \%$ \\
\hline 28 & 6 & $100 \%$ & 15 & $100 \%$ & 21 & $100 \%$ \\
\hline 29 & 5 & $83 \%$ & 14 & $93 \%$ & 19 & $90 \%$ \\
\hline 30 & 6 & $100 \%$ & 13 & $87 \%$ & 19 & $90 \%$ \\
\hline
\end{tabular}


Table 3 summarizes the frequencies and percentages of answers for individual questions for the experimental and control group as an aggregate. All 21 participants answered six questions (20\%) correctly. A majority of questions, 18 (60\%) were answered correctly by greater than $50 \%$ of the participants. Six questions were answered incorrectly by a majority (greater than 50\%) of the participants. 
Table 3

Total frequencies and percentages of answers for individual questions on the NTCC

Exam (Correct answer highlighted) Frequency \%

1. How do drug resistant strains of Mycobacterium tuberculosis most commonly develop?

Spread of more virulent strains of M. tuberculosis from Asia $\quad 1 \quad 5 \%$

$\begin{array}{lll}\text { The use of drugs to treat animals in the food supply } & 0 & 0\end{array}$

Failure of patients to adhere to the medication regime $\quad 16 \quad 76 \%$

Drugs being overused for lung infections other than M. tuberculosis $\quad 4 \quad 19 \%$

2. What is the natural reservoir for Mycobacterium tuberculosis?

Humans

$17 \quad 81 \%$

Dry, alkaline soil

$210 \%$

Insects

$0 \quad 0$

Salt and fresh water

$210 \%$

3. Which of the following is the screening test for TB in which purified protein derivative (PPD) is injected under the skin of the forearm?

Mantoux

QuantiFERON

$21 \quad 100 \%$

Lowenstein-Jensen

$0 \quad 0$

Middlebrook

$0 \quad 0$

$0 \quad 0$

4. The Mantoux test is best described as:

A diagnostic test for active TB $\quad \begin{array}{ll}0 & 0\end{array}$

An intradermal screening test for TB infection $\quad 21 \quad 100 \%$

An interferon gamma assay test for TB $\quad 0 \quad 0$

$\begin{array}{lll}\text { A test which distinguishes active and latent TB } & 0 & 0\end{array}$

5. Which of the following tests is performed in the laboratory as a test on blood to identify patients who have been infected with $M$. tuberculosis?

Mantoux test

$314 \%$

Nucleic acid amplification test

$15 \%$

AFB smear

$524 \%$

Interferon Gamma release assay (QuantiFERON-TB Gold) $\quad 12 \quad 57 \%$

6. Which of the following is the best nursing diagnosis for a patient with active TB disease who is experiencing loss of appetite and weight loss?

Altered health maintenance

Risk for disturbed body image

$15 \%$

$0 \quad 0$ 
Noncompliance

Altered nutrition less than body requirements

$0 \quad 0$

$20 \quad 95 \%$

7. How soon after exposure to Mycobacterium tuberculosis will a skin or blood test for latent TB infection (LTBI) become positive?

Within one week

Within 12 weeks

Between 6 and 8 months

After one year

$\begin{array}{cc}2 & 10 \% \\ 14 & 67 \% \\ 1 & 5 \% \\ 4 & 19 \%\end{array}$

8. In an otherwise healthy adult patient without risk factors for acquisition of TB, which of the following measurements of induration would constitute a positive result after a properly placed purified protein derivative (PPD) tuberculin skin test?

$<5 \mathrm{~mm}$

$6 \mathrm{~mm}$ to $10 \mathrm{~mm}$

$0 \quad 0$

$\geq 15 \mathrm{~mm}$

$1362 \%$

$11 \mathrm{~mm}$ to $14 \mathrm{~mm}$

$210 \%$

$6 \quad 29 \%$

9. Mycobacterium tuberculosis is transmitted through which route?

Ingestion of contaminated water

Contact with fomites (i.e. inanimate objects) in the hospital 0

Inhalation of aerolized droplets

Cutaneous exposure to infected blood or body fluids

$21 \quad 100 \%$

00

10. According to the most recent data reported by the Centers for Disease Control and Prevention (CDC), approximately what percentage of newly diagnosed TB cases in the U.S. occurs in foreign-born persons?

$40 \%$

$20 \%$

$50 \%$

$943 \%$

$30 \%$

$15 \%$

$9 \quad 43 \%$

$210 \%$

11. Bacille Calmette-Guerin (BCG) vaccination for TB is rarely used in the US for which of the following reasons?

I. It interferes with TB skin testing

II. The low risk of $\mathrm{TB}$ in the overall US population

III. The variability of the vaccine in preventing pulmonary TB

I and II only

II only

I, II, and III

$3 \quad 14 \%$

II and III only

$210 \%$

$1152 \%$

$524 \%$ 
12. What co-morbid disease/condition was primarily responsible for the resurgence of TB in US in the late 1980s?

Asian flu

Lung Cancer

$210 \%$

Malaria

$0 \quad 0$

HIV/AIDS

$15 \%$

$18 \quad 86 \%$

13. After the initiation of TB surveillance in 1953, TB case rates in the US steadily declined until 1985 when case rates began to climb. What were the causes of this TB resurgence?

I. Better reporting of TB cases by health departments

II. HIV epidemic

III. Immigration from TB endemic countries

IV. Spread of TB in high risk settings (e.g. homeless shelters)

$V$. Inadequate funding for TB control and public health

II, III, IV and V only

II only

I only

$1571 \%$

IV and V only

$0 \quad 0$

14. Which of the following would be the first independent nursing intervention used in working with a patient strongly suspected of having an infectious respiratory disease such as tuberculosis?

Open windows and doors to the room to help "air out" the room $\quad \begin{array}{lll}0 & 0\end{array}$

Initiate antibiotic therapy with the appropriate drug $\quad 1 \quad 5 \%$

Collect and send sputum culture to the laboratory $\quad 0 \quad 0$

Institute airborne infection isolation (AII) precautions $\quad 20 \quad 95 \%$

15. The best way to ensure TB patients take their medication is to:

$\begin{array}{lll}\text { Have someone watch the patient swallow each dose of medication } & 7 & 33 \%\end{array}$

$\begin{array}{lll}\text { Measure serum drug levels } & 2 & 5 \%\end{array}$

Make sure the patient understands the importance of taking the medication $\quad 11 \quad 52 \%$

$\begin{array}{lll}\text { Ask patients if they are taking their medications } & 1 & 5 \%\end{array}$

16. Which of the following is a special ventilation requirement for rooms that house TB patients or for labs conducting TB testing?

Negative air pressure

Positive air pressure

Sterile air is vented into the areas

Rooms should be kept cooler than surrounding areas

$20 \quad 95 \%$

$15 \%$

$0 \quad 0$

$0 \quad 0$ 
17. Which of the following signs and symptoms best characterize a patient with latent TB infection (LTBI)?

A negative TB skin test, obvious clinical symptoms and a positive sputum $1 \quad 5 \%$ culture

A positive TB skin test, a few clinical symptoms and a positive sputum $\quad 3 \quad 14 \%$ culture

A negative TB skin test, some clinical symptoms and a normal chest x-ray $\begin{array}{lll}0 & 0\end{array}$

A positive TB skin test, no clinical symptoms and a normal chest X-ray $\quad 17 \quad 81 \%$

18. What is the person with latent TB infection (LTBI) taught about their ability to transmit TB to another person?

They should wear a mask to reduce the risk of transmitting TB infection $\quad 6 \quad 29 \%$

Exposed persons to TB infection should be quarantined $\quad 0 \quad 0$

They are highly infective and isolation precautions should be initiated $\quad 3 \quad 14 \%$

$\begin{array}{lcl}\text { They cannot transmit TB infection } & 12 \quad 57 \%\end{array}$

19. Which of the following poses the greatest risk for latent $T B$ to progress to active TB?

Poverty and malnutrition $\quad 3 \quad 14 \%$

Co-infection with HIV $\quad 10 \quad 48 \%$

Working in a laboratory $\quad \begin{array}{lll}0 & 0\end{array}$

$\begin{array}{lll}\text { Concurrent lung disease such as asthma or pneumonia } & 8 & 38 \%\end{array}$

20. Which of the following are the most common clinical features of pulmonary TB?

Chills, edema and shortness of breath

Swollen lymph nodes, painful joints and fatigue

Cough, weight loss and night sweats

$2 \quad 10 \%$

Headache, disorientation and difficulty breathing

$1990 \%$

21. What is the most common route of transmission of Mycobacterium tuberculosis?

Eating food contaminated with $M$. tuberculosis bacilli $\quad 0 \quad 0$

$\begin{array}{lll}\text { Drinking water contaminated with } M \text {. tuberculosis bacilli } & 0 & 0\end{array}$

Breathing in M. tuberculosis bacilli found on fomites (bed sheet, utensils $\quad \begin{array}{lll}0 & 0\end{array}$

Breathing in contaminated droplet nuclei generated from coughing or $\quad 21 \quad 100 \%$ sneezing

22. In order to control the transmission of TB in hospitals, patients suspected of or known to have active pulmonary or laryngeal TB are housed in airborne infection isolation (AII) rooms. One of the engineering standards for these rooms relates to air pressure. Which type of air pressure is correct for an AII room?

Variable

$0 \quad 0$

Positive 
Neutral

$2 \quad 10 \%$

Negative

$1990 \%$

23. To obtain the latest information on TB case rates in the United States, you should locate the website of which of the following organizations?

Your local health Department

Centers for Disease Control and Prevention

$0 \quad 0$

Any school of public health in your state

$21 \quad 100 \%$

United Nations

$0 \quad 0$

24. What organization should one contact to obtain the latest information on the incidence of TB internationally?

Peace Corps website

Centers for Disease Control and Prevention (CDC) website

US Agency for International Development (USAID) website

World Health Organization (WHO) website

$\begin{array}{cc}0 & 0 \\ 3 & 14 \% \\ 0 & 0 \\ 18 & 86 \%\end{array}$

25. A TB case diagnosed by a private physician in his/her office should be reported to:

The Centers for Disease Control and Prevention $\quad 13 \quad 62 \%$

$\begin{array}{lll}\text { The state health department } & 8 & 38 \%\end{array}$

No one, as reporting violates confidentiality $\quad 000$

The state medical society

$0 \quad 0$

26. The most important public health practice in the control and the interruption of transmission of tuberculosis is the:

Universal tuberculin skin test (TST) or blood assay for M. tuberculosis $\quad 1 \quad 5 \%$

(BAMT) evaluation of children entering school

Bacille Calmette-Guerin (BCG) vaccination

$0 \quad 0$

Rapid identification and treatment for all persons with active pulmonary $\quad 15 \quad 71 \%$

TB

Use of N95 respirators by health care workers

$5 \quad 24 \%$

27. Which of the following groups is the highest priority for public health professionals in the United States who are employing targeted testing and treatment of latent TB infection (LTBI)?

Children entering school for the first time

$0 \quad 0$

Close contacts of active TB cases

$7 \quad 33 \%$

Injection drug users

$210 \%$

Persons immigrating to the US from high TB prevalence areas

$1257 \%$

28. Which of the following two signs and symptoms are characteristic of pulmonary TB but not typical of community-acquired pneumonia? 
Cough and fever

Weight loss and night sweats

$0 \quad 0$

Fever and chills

$21 \quad 100 \%$

Cough and sputum production

29. Which of the following is the most applicable nursing assessment for a patient with newly diagnosed active TB disease who states "I can protect my family from tuberculosis by not touching any of them."?

Disturbed thought processes related to solation

Altered protection related to impaired stress response

Risk for disease transmission related to lack of knowledge

Ineffective denial related to increased anxiety

$\begin{array}{cc}0 & 0 \\ 1 & 5 \% \\ 19 & 90 \% \\ 1 & 5 \%\end{array}$

30. Mr. James, a homeless patient diagnosed with active TB disease states "I feel so alone and rejected by my friends." Of the following, which is most appropriate nursing diagnosis for this patient?

Risk of powerlessness

$0 \quad 0$

Impaired adjustment

$15 \%$

Risk for loneliness

$15 \%$

Social Isolation

$19 \quad 90 \%$


Participant comments stated that the case studies were helpful for clinical information on TB, but lacked a basic tutorial about the signs, symptoms, treatments, epidemiology and the nursing implications. They felt the case studies were interesting, but that the NTCC site did not provide enough instruction prior to the case studies as to the mechanics of using the site. A request was made that even though the consent contained the purpose of the study, that the purpose be included in the emails sent to the participants. One participant commented that the case studies were a "great way to get some more knowledge on TB. It is covered briefly in class, but the case studies helped to clarify and also helped to gain more knowledge." Another comment indicated that the number of questions caused the participant to lose focus a bit, and that "some of the questions were very wordy, and I had to read a few times to be sure I understood exactly what you were asking." 


\section{Summary and Conclusions}

This experimental study was designed to evaluate if the addition of NTCC developed online learning modules to a baccalaureate nursing curriculum had an effect on the students' knowledge of tuberculosis (TB). During the fall 2012 semester third year baccalaureate nursing students were recruited from Adult Health Nursing I to participate in the study. This course was chosen because the main components of TB education in the baccalaureate curriculum were included in the respiratory content covered near the end of the semester.

The investigator visited the two class sections of the course and provided students with information about the reasons for the study, the design of the study, and the amount of work that could be expected if they participated. As an incentive, students who completed the entire study were told they would receive a $\$ 10.00$ coffee shop gift card. A consent form was given to any student who requested one. Students were very receptive to the idea of participating in the study, as evidenced by the initial enrollment of 38 students out of a total of 47 students in both sections. Students who agreed to participate provided their e-mail addresses, and were told that all communication for the rest of the study would be done via e-mail.

A demographic questionnaire was sent to all 38 participants shortly after the initial sign-up. The decision to do this so early in the project was made in order to make contact with the students and let them know the study was underway. In retrospect, it would have been better to request demographic information when the groups had been randomized into experimental and control groups, or even when the final exam results 
were submitted, since then the data would have been more specific to the study participants. Thirty (79\%) students completed the demographic information, and as the study progressed, the trend of decreased participation continued, with the numbers decreasing at each stage of the study.

The students who agreed to be in the study were randomized into two groups, experimental and control. There were 19 students in each group. The students in the control group were notified that they needed to do nothing until they would be asked to complete a multiple choice exam after the TB content had been covered in class. Fifteen (79\%) members of the control group would go on to complete the entire study, as evidenced by their submission of the completed multiple-choice exam. The experimental group was sent detailed instructions on how to register on the NTCC website, and 11 (58\%) did so. Six (32\%) completed the online modules, and all six of them went on to submit the completed multiple-choice exam.

The members of the experimental group were required to do far more work to complete the study, and this is reflected in the higher drop out rate of participants assigned to the experimental group compared to the control group. The members of the experimental group who demonstrated initiative not only to complete all three of the case studies, but to complete the multiple-choice exam as well, support Knowles theory of self-directed learning. They took the time and had a willingness to develop knowledge independently, and were motivated to complete content that had no direct connection to course requirements. 
The mean of the raw scores on the multiple-choice exam for the experimental group was higher than that of the control group (see Table 1). The medians of the raw scores of the two groups were equivalent. The small sample size prevented analysis of the results for statistical significance. The experimental group had a higher frequency of correct answers for $15(50 \%)$ of the exam questions, while the control group had a higher frequency of correct answers for $8(27 \%)$ of the questions (see Table 2). The range of scores earned by the control group was broader than the experimental group, with members of the control group scoring both higher and lower than the experimental group. Again, the difference in sample size prevents statistical analysis, but the results indicate that the students who completed the case studies were able to answer a greater percentage of questions correctly than those who did not complete the case studies.

A majority of both groups answered some questions incorrectly, and it is interesting to examine the answers they chose, and postulate why. For example, question 8 (see Table 3) asked students about the guidelines for determining whether a patient can be considered to have a positive PPD reading based on risk factors. Only $10 \%$ answered the question correctly. The addition of a Basic TB Skin Test Course to the baccalaureate curriculum, as described by Stone (2001) would address this knowledge deficit.

Question 15 reflects the concept of directly observed therapy (DOT), a widely used method to ensure that patients take every dose of prescribed medication; because of the emergence of drug-resistant strains of $\mathrm{TB}$, it is especially important that patients do not stop therapy before it is complete or skip doses. Only $33 \%$ of students picked the 
correct answer-instead the majority (52\%) chose the answer "make sure the patient understands the importance of taking the medication." Nursing students at this stage of their education are learning the importance of involving patients in their own care, so it would make sense that this would be their choice, and even though it is incorrect in relation to TB therapy, it is appropriate for many other situations.

Question 25 asked students to whom a private physician should report a case of TB that was diagnosed in his/her office. The majority (62\%) answered the Centers for Disease Control and Prevention (CDC), while only 38\% correctly indicated that it should be reported to the state health department. Students enrolled in Adult Health Nursing I in the fall semester will go on to enroll in a public health nursing course in their senior year. As part of that curriculum, they will learn about the role of the state health department, and how reporting starts at the local level.

Some comments made by students would indicate that the NTCC site lacked preliminary instruction on how to maneuver through the case studies. Also, one student felt there could have been a basic tutorial about TB on the site. Since the materials were developed to augment classroom instruction, the developers may have felt that this would be covered in the basic curriculums of the healthcare students. However, it is a valuable suggestion to make the NTCC page more user friendly and informative for any level of student who wants to access it.

The low number of participants who completed the entire study, and the variance in numbers between the experimental and control group limited the ability of the 
investigator to draw any statistically significant conclusions. Nursing students in the fall semester of their third year have a demanding schedule of classroom and clinical obligations, so it was not the optimal time to ask students to take on additional work. This weakness could be addressed by recruiting students earlier in the semester, allowing them several weeks to complete the assigned modules. The fact that so many students expressed an interest in participating, as well as the number who eventually completed the study was very heartening, and reflects the emphasis that the Rhode Island College nursing program places on supporting colleagues and research activities.

Designing and implementing an experimental study is a significant challenge for a first time investigator. Once the IRB proposal has been approved, there can be no variation from the procedures as outlined in the proposal. This is significant, because there is no option to change procedures when issues are identified during the study, such as decreasing the number of case studies, or the number of questions on the multiple choice exam, without going back to the IRB. As the study progressed, it became clear that the amount of work required for the students, especially those in the experimental group, was significant. For a public health nurse, tuberculosis is an extremely interesting topic, but for baccalaureate nursing students it is just one of many clinical issues that they are trying to learn about when considering respiratory medical problems.

Rather than trying to determine the effect of online learning modules on students' knowledge of tuberculosis, it might have been more informative to do a study on how effectively the current baccalaureate nursing content at Rhode Island College addresses 
the topic of TB. The multiple choice exam used in the study could have been given as a pre-test at the beginning of the semester, then as a post-test after the content had been covered. This would have determined a baseline for the effectiveness of the current curriculum. The addition of the online modules to the content could then be piloted the next time the course is taught, with the same pre-test/post-test being administered. 


\section{Implications for Advanced Nursing Practice}

Teaching is a core competency at all levels of nursing. While we often focus on the education of patients, for Masters prepared nurses the additional qualification of educating nursing students is added to the responsibilities of practice. This study focused on the knowledge of TB among a group of third year baccalaureate nursing students, and strived to determine if the addition of online learning modules had an effect on their knowledge outcomes. While the study was inconclusive, it did reveal that working with nursing students to advance their knowledge on a topic is both challenging and rewarding.

$\mathrm{TB}$ as a disease gives nursing faculty an opportunity to discuss not just signs and symptoms, but epidemiology, public health practices, global health, politics, and the inability of medicine to eliminate a disease that has a known cure. It is the responsibility of advanced practice nurses to educate themselves about topics such as TB, so that they can present accurate and multi-faceted instruction to the baccalaureate-nursing students they will be teaching.

Advanced practice nurses (APRNs) in public health serve as infectious disease specialists in county and state health departments. Current and accurate knowledge related to TB is essential in order for APRNs to educate not only their patients, but also other health care providers about the complex interactions between the disease and the social determinants of health, such as homelessness, poverty, and lack of access to health care and immigration status. The information on the NTCC website can be utilized by 
APRNs to enhance their continuing education related to TB.

Persons born outside of the United States are far more likely to be infected with tuberculosis than those born in the U.S., and public health nurses must be able to communicate accurate and timely information to this population, especially regarding LTBI and the risk for development of active TB.

Information concerning the effect of BCG vaccination on testing for LTBI is often inaccurate and leads to under treatment of the infection-every case of active TB started as a case of latent TB. APRNs must develop cultural competency in order to build trust with people who have emigrated from countries where TB is prevalent. When active cases are diagnosed, APRNs must be able to communicate effectively in order to engage in the complex case finding and treatment that is necessary to limit the spread of the disease, especially within and to children.

APRNs can assume a leadership role in correcting misconceptions about TB that can be prevalent in the medical community. In New England, six states (Connecticut, Maine, Massachusetts, New Hampshire, Rhode Island and Vermont) have formed a TB Consortium that meets on a regular basis to provide a framework for strengthening programs by establishing common goals and objectives. The consortium consists of public health officials, civil surgeons, social workers, infectious disease specialists and community health workers as well as nurses. The interdisciplinary nature of this organization strengthens the work that is done across the communities. APRNs have the leadership responsibility to seek out opportunities to become involved in organizations 
such as this and take on active roles.

The demographic information gathered from the students in this study indicated that $80 \%$ were between the ages of 18 and 27 . These students are very comfortable with technology, as evidenced by their ability to use electronic communication throughout the entire study, and to access the NTCC materials online and complete the case studies with very little difficulty. Further research needs to be done on how to incorporate online learning and other forms of technology into nursing curriculums as well as methods to measure the most effective teaching tools.

APRNs can also influence policy related to TB screening, treatment and elimination of TB on the local level. In October 2012, hearings were held at the Rhode Island Department of Health concerning the revision of disease screening and prevention regulations for Health Care Workers (HCW). While much of the attention was focused on the inclusion of a mandate for flu vaccination for $\mathrm{HCW}$, there was also a revision to the regulations regarding treatment of HCW who test positive for LTBI after January 1, 2013. Previously, it had been recommended that these individuals receive prophylactic treatment, but now they will be required to complete a plan of treatment (Rhode Island Department of Health, 2012). According to Patricia Raymond, MSN, RN, Immunization Program Manager for Rhode Island, the changes were made based on recommendations received from the public health community, including APRNs. This type of policy change, and its continued enforcement, are part of safety and quality efforts directed at ensuring that that patients are not exposed to infectious disease from workers in the 
health care system.

Masters prepared nurses, as leaders in the profession, are responsible for ensuring that the nursing students who follow them are prepared to face the complex challenges of health care. Those students, the next generation of nurse researchers, need to be encouraged to continue to move the knowledge of the profession forward. Involving baccalaureate-nursing students in research about effective teaching methods, as well as giving them additional information on complex health topics such as TB is one way to accomplish that goal. 


\section{References}

Akin, S., Gorak, G., Unsar, S., Mollaoglu, M., Ozdilli, K., \& Durna, Z. (2011).

Knowledge of attitudes toward tuberculosis of Turkish nursing and midwifery students. Nurse Education Today, 31(8): 774-779.

Belcher, A., Conner, L., Anderson, J. M., Branham, J., Levett, M., Paddock, G., Printy, G., Printy, J., Showalter, R. \& Zonca, M. (2011). Education-service partnership to promote best practices in a latent tuberculosis infection program. Public Health Nursing, doi: 10.1111/j.1525-1446.2011.00977.x

Benkert, R., Resnick, B., Brackley, M., Simpson, T., Fair, B., Esch, T., \& Field, K. (2009). Tuberculosis education for nurse practitioner students: Where we are and where we need to go. Journal of Nursing Education, 48(5): 255-265.

Bennett, D. E., Courval, J. M., Onorato, I., Agerton, T., Gibson, J. D., Lambert, L., McQuillen, G. M., Lewis, B., Navin, T. R., \& Castro, K. G. (2008). Prevalence of tuberculosis infection in the United States: The national health and nutrition examination survey, 1999-2000. American Journal of Respiratory Care and Critical Care Medicine, 177: 348-355.

Brudney, K. \& Dobkin, J. (1991). Resurgent tuberculosis in New York City: Human immunodeficiency virus, homelessness, and the decline of tuberculosis control programs. American Journal of Respiratory Care and Critical Care Medicine, 144(4): 745-749. 
Centers for Disease Control and Prevention (2012). Trends in tuberculosis: United States, 2011. Morbidity and Mortality Weekly Report, 61(11): 181-185.

Cook, D. A., Levinson, A. J., Garside, S., Dupras, D. M., Erwin, P. J., \& Montori, V. M. (2008). Internet-based learning in the health professions: A meta-analysis. Journal of the American Medical Association, 300(10): 1181-1196.

DeSanto-Madeya, S. (2007). Using case studies based on a nursing conceptual model to teach medical-surgical nursing. Nursing Science Quarterly, 20(4): 324-326.

Fair, B. S., Esch, T. J., Simpson, T., Field, K., Benkert, R., Brackley, M., \& Resnick, B. (2006). Educational competencies to strengthen tuberculosis curricula in undergraduate nursing programs. International Journal of Nursing Education Scholarship, 3(1) 23. Retrieved from: http://www.bepress.com/ijnes/vol3/iss1/art23

Harrity, S., Jackson, M., Hoffman, H., \& Catanzaro, A. (2007). The National Tuberculosis Consortium Curriculum: A model of multi-disciplinary educational collaboration. International Journal of Tuberculosis and Lung Diseases, 11: 270274.

Hinski, S. T., Goodfellow, L. T., Bryant, L. O., \& Zimmerman, R. (2011). Survey of knowledge and confidence of respiratory therapy students regarding tuberculosis. Respiratory Care Education Annual, 20: 45-62.

Institute of Medicine (2000). Ending neglect: The elimination of tuberculosis in the United States. Washington, DC: National Academies Press. 
Jackson, M., Harrity, S., Hoffman, H., \& Catanzaro, A. (2007). A survey of health professions students for knowledge, attitudes, and confidence about tuberculosis, 2005. BMC Public Health, 7(219).

Keppel, K. G. (2007). Ten largest racial and ethnic health disparities in the United States based on Healthy People 2010 objectives. American Journal of Epidemiology, 166: $97-103$.

Khan, K., Wang, J., Hu, W., Bierman, A., Li, Y., \& Gardam, M. (2007). Tuberculosis infection in the United States: National trends over three decades. American Journal of Respiratory Care and Critical Care Medicine, 177: 455-460.

Knowles, M. S. (1970). The modern practice of adult education: Andragogy versus pedagogy. New York, NY: Association Press.

Knowles, M. S. (1975). Self-directed learning: A guide for learners and teachers. New York, NY; Association Press.

Lashley, M. (2007). Nurses on a mission: A professional service learning experience with the inner city homeless. Nursing Education Perspectives, 28(1). Retrieved from http://www.freepatentsonline.com/article/Nursing-EducationPerspectives/159534797.html

Means, B., Toyama, Y., Murphy, R., Bahia, M., \& Jones, K. (2010). Evaluation of evidence-based practice in online learning: A meta-analysis and review of online learning studies. Technical Report, U.S. Department of Education, Washington, D.C. 
Moore, P. (1998). Actions taken by nursing education programs in the United States to prevent tuberculosis transmission in nursing students. Journal of Nursing Education, 37(3): 101-108.

National Tuberculosis Curriculum Consortium (2010, June). Active learning: How to use the NTCC website for learning and teaching TB. Retrieved from http://ntcc.ucsd.edu/

Schoener, L. \& Hopkins, M. L., (2004). Service learning: A tuberculosis-screening clinic in an adult residential care facility. Nurse Educator, 29(6): 242-245.

Shah, N. S., Pratt, R., Armstrong, L., Robison, V., Castro, K.G., \& Cegeielski, J. P. (2008). Extensively drug-resistant tuberculosis in the United States, 1993-2007. Journal of the American Medical Association, 300(18); 2153-2160.

State of Rhode Island and Providence Plantations Department of Health (2012). Rules and regulations pertaining to immunization, testing and health screening for health care workers [R23-17-HCW], section 3.5.5: 8-9.

Stone, C. L. (2001). Building academic and practical knowledge in nursing through TB skin testing certification in a BSN curriculum, Public Health Nursing, 18(3): 212215.

Villa, T. C. S., Ruffino-Netto, A., Andrade, R. L. P., Alarcon, E. A., Montero, C. V., \& Firmino, D., R. (2006). Survey on tuberculosis in Brazilian nursing schools, 2004. The International Journal of Tuberculosis and Lung Disease, 10: 323-327. 
World Health Organization (2012). Fact sheet N104 tuberculosis. Retrieved from: http://www.who.int/mediacentre/factsheets/fs104/en/ 


\section{Appendix A \\ CONSENT DOCUMENT \\ Rhode Island College}

Online Learning Modules and Nursing Students' Knowledge of Tuberculosis

You are being asked to participate in a research study about whether the use of online learning modules has an effect on Baccalaureate Nursing Students' knowledge of tuberculosis. You were selected as a possible participant because you are enrolled in Nursing 342 and will receive classroom instruction this semester on the topic of tuberculosis as part of the respiratory section of the curriculum. Please read this form and ask any questions that you may have before deciding whether to be in the study.

Monica Kunkel, BSN, RN-C, a Masters degree student in the School of Nursing at Rhode Island College, is conducting this study. Professor Mary Byrd, School of Nursing, is the faculty advisor for the study.

\section{Background Information}

The purpose of this research is to see if the use of interactive online learning modules that use real-life case studies has an effect on students' knowledge of tuberculosis.

\section{Procedures}

If you choose to be a participant in this research, you will be asked to do the following things

- Agree to be randomly assigned to a control or experimental group

- If assigned to the experimental group, you will be sent three online modules over the course of the semester that take approximately one hour each to complete.

- After the respiratory content in NURS 342 relating to TB has been presented, both groups will be e-mailed a 30 question multiple-choice test to be completed and emailed back.

- You will receive a \$10.00 Dunkin' Donuts gift card for your participation at the completion of the study

\section{Risks of Being in the Study}

The risks of participating in this research are minimal, meaning that they are about the same as you would experience in your normal daily activities.

\section{Benefits to You}

The experimental group will receive additional instruction that may be helpful in the course. At the end of the study, both groups will be given information on how to utilize the online modules that could assist them in preparing for the NCLEX. 


\section{Voluntary Participation}

Your participation is completely voluntary. The School of Nursing or your professor does not require it. You can choose not to participate in this research and it will have no effect on your grade for NUR 342. Also, you can change your mind about participating at any time with no negative consequences.

\section{Confidentiality}

The records of this research will be kept private. In any sort of report that might be published, the researcher will not include any information that will make it possible to identify you. Research records will be kept in a secured file, and access will be limited to the researcher. If there are problems with the study, the research records may be viewed by Rhode Island College review board responsible for protecting human participants and other government agencies that protect human participants in research. All data will be kept for a minimum of three years, after which it will be destroyed.

\section{Contacts and Questions}

The researcher conducting this study is Monica Kunkel, BSN, RN-C. You may ask any questions you have now. If you have any questions later, you may contact her at Monica.Kunkel@gmail.com or 401-241-8696. Professor Mary Byrd, the faculty advisor for the project can be contacted at mbyrd@ric.edu. Her office is Fogarty Life Science $221,401-456-8013$ or $401-456-9764$.

If you think you were treated unfairly or would like to talk to someone other than the researcher about your rights or safety as a research participant, please contact Dr.

Christine Marco, Chair of the Rhode Island College Institutional Review Board at

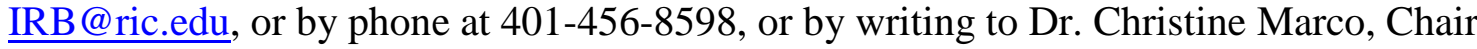
IRB; c/o Department of Psychology, Horace Mann Hall 311; Rhode Island College; 600 Mount Pleasant Avenue; Providence, RI 02908.

You will be given a copy of this form for your records. 


\section{Appendix B}

\section{Tuberculosis Research Study Demographic Questionnaire}

Thank you for agreeing to participate in my research study about baccalaureate nursing students and knowledge of tuberculosis. As part of my data collection, I am requesting that you provide some basic demographic information that will be valuable in reporting my results. This data is for general purposes only, and will not be tied to an individual and/or their test results.

${ }^{*}$ Required

Are you a tradtional or second degree student? *

- $\square$ Traditional

- $\square$ Second degree

- $\square$ Other:

Please indicate your gender *

- $\square$ Male

- $\square$ Female

Please indicate your age *

- $\square$ 18-22

- $\square 23-27$

- $\square$ 28-30

- $\square 1-35$

- $\square$ 36-40

- $\square$ >than 40

Please indicate the ethnic/racial group you most closely identify yourself with: *

- $\square$ Hispanic

- $\square$ Portuguese

- $\square$ African-American

- $\square$ Asian/Pacific Islander

- $\square$ Caucasion

- $\square$ I prefer not to say

- $\square$ Other: $\square$

\section{Submit}




\section{Appendix C}

Thank you for agreeing to participate in my research study.

You have been randomly assigned to the control group, so if you have completed the demographics questionnaire I recently e-mailed you

then you have nothing further to do at this time. If you have not completed the questionnaire, please do so now.

I will be in touch in the next few weeks.

Thank you, Monica 


\section{Appendix D}

Thank you for agreeing to participate in my research study.

You have been randomly assigned to the experimental group and will be asked to complete three online learning modules.

In order to access the modules, you will need to register as a student on the National Tuberculosis Curriculum Consortium website.

It is free and only takes a few minutes.

Here are the instructions:

Go to: ntcc.ucsd.edu

In the upper right hand corner of the home page click on Register Here This will bring you to the next page that will ask for your name, e-mail, and to create a username and password

Pick STUDENT for the options PLEASE WRITE DOWN YOUR USERNAME AND PASSWORD--YOU WILL NEED IT TO LOG ON TO THE SITE LATER

On the next page:

Choose: Nursing, Baccalaureate

Enter the demographic information

CHOOSE INDEPENDENT STUDY

Answer the rest of the questions, then submit.

You will receive an e-mail confirming your registration--please forward me a copy at Monica.Kunkel@gmail.com so I know you have access to the site.

I will be sending you an e-mail after I receive your registration confirmation telling you which three modules are included in the study.

Please REMEMBER YOUR USERNAME AND PASSWORD--try storing them in your phone under TB study.

Also, if you have not completed the Tuberculosis Demographic questionnaire that I sent in a previous e-mail, please do so now.

Thank you and I will be in touch--don't forget that Dunkin' Donuts gift card that awaits you at the end!!! 


\section{Appendix E}

I have not heard from you, so I assume you have decided not to register on the NTCC website. That is fine, but it means that you cannot complete the study. If you wish to continue, please refer to my previous e-mail about registering. Otherwise, I will remove your name from the list.

Please let me know if you have any questions, I appreciate your interest in my study, and I understand if you cannot continue.

Thank you,

Monica 


\section{Appendix F}

Here are the instructions on how to access the three case studies that you have been asked to complete for my research study. You can complete them at your own pace over the next few weeks. You will be able to email them to me through the site as you complete them. Please try to get all three to me by November 25 .

Log on to the NTCC website with your user name and password.

Click on the online learning modules

Next to where it says select any audience, use the drop down menu to choose BSN

The first three case studies:

Moss, George

Smith, Ederlina and Rolando

Stewart, Linda

are the ones chosen for this research study

Click on the name of the patient, and choose 1) Run the case from the web In the lower right hand corner of the next page click on the arrow next to Enter Case

Proceed through the pages. You have to enter something in the boxes in order to continue or see the expert opinions--if you would rather just see the opinions, just type in a letter and then click twice on the box.

There are no right or wrong answers, this is strictly a way to learn more about TB

When completed, you will be able to email me the case study at monica.kunkel@gmail.com

Please also put your name so I know you have seen the material.

Thank you so much for continuing to participate in this study. Please email me if you have any questions or problems. 


\section{Appendix G}

\section{Tuberculosis Study Completion Exam}

Just a reminder--please complete and submit the exam! This is it! Once you complete this exam and hit submit you will be done with the study--I bet you can taste that Dunkin Donuts coffee now! Please don't worry about grades--it is better if this is just a raw measure of your knowledge. I have left a place at the end for you to put your name- -this is just to know what group (experimental or control) to assign the results to (and also to know who gets a gift card) Also, I have left a space for you to include any comments you might have. Thank you again for participating in this study!!

${ }^{*}$ Required

How do drug resistant strains of Mycobacterium tuberculosis most commonly develop? *

- $\bigcirc$ spread of more virulent strains of M. tuberculosis from Asia

- $\bigcirc$ The use of drugs to treat animals in the food supply

- $\bigcirc$ Failure of patients to adhere to the medication regime

- $\bigcirc$ Drugs being overused for lung infectionsother than M. tuberculosis

What is the natural reservoir for Mycobacterium tuberculosis? *

- Humans

- $\bigcirc$ Dry, alkaline soil

- $O$ Insects

- Salt and fresh water

Which of the following is the screening test for TB in which purified protein derivative (PPD) is injected under the skin of the forearm? *

- $\bigcirc$ Mantoux

- QuantiFERON

- $O$ Lowenstein-Jensen

- $\bigcirc$ Middlebrook

The Mantoux test is best described as: *

- $\bigcirc$ A diagnostic test for active TB

- $\bigcirc$ An intradermal screening test for TB infection

- $\bigcirc$ An interferon gamma assay test for TB infection

- $\bigcirc$ A test which distinguishes active and latent TB 
Which of the following tests is performed in the laboratory as a test on blood to identify patients who have been infected with M. tuberculosis? *

- $\bigcirc$ Mantoux test

- $\bigcirc$ Nucleic acid amplification test

- $\bigcirc$ aFB smear

- $\bigcirc$ Interferon Gamma release assay (Quantiferon-TB Gold)

Which of the following is the best nursing diagnosis for a patient with active TB disease who is experiencing loss of appetite and weight loss? *

- $\bigcirc$ Altered health maintenance

- $\bigcirc$ Risk for disturbed body image

- Noncompliance

- $\bigcirc$ Altered nutrition less than body requirements

How soon after exposure to Mycobacterium tuberculosis will a skin or blood test for latent TB infection (LTBI) become positive? *

- $\bigcirc$ Within one week

- $\bigcirc$ Within 12 weeks

- Between 6 and 8 months

- $\bigcirc$ After one year

In an otherwise healthy adult patient without risk factors for acquisition of TB, which of the following measurements of induration would constitute a positive result after a properly placed purified protein derivative (PPD) tuberculin skin test? *

- $\bigcirc$ less than $5 \mathrm{~mm}$

- $6 \mathrm{~mm}$ to $10 \mathrm{~mm}$

- $\bigcirc$ greater than $15 \mathrm{~mm}$

- $11 \mathrm{~mm}$ to $14 \mathrm{~mm}$

Mycobacterium tuberculosis is transmitted through which route? *

- Ingestion of contaminated water

- $\bigcirc$ Contact with formites (i.e. inanimate objects) in the hospital

- Inhalation of aerolized droplets

- $\bigcirc$ Cutaneous exposure to infected blood or body fluids 
According to the most recent data reported by the Centers for Disease Control and Prevention (CDC), approximately what percentage of newly diagnosed TB cases in the U.S. occurs in foreign-born persons? *

- $\bigcirc 40 \%$
- $\bigcirc 20 \%$
- $\bigcirc 50 \%$
- $\bigcirc 30 \%$

Bacille Calmette-Guerin (BCG) vaccination for TB is rarely used in the US for which of the following reasons? $* 1$. It interferes with TB testing 2 . The low risk of TB in the overall US population 3 . The variability of the vaccine in preventing pulmonary TB

- 1 and 2 only

- 2 only

- 1,2 and 3

- 2 and 3 only

What co-morbid disease/condition was primarily responsible for the resurgence of TB in US in the late 1980 s? *

- $\bigcirc$ Asian flu

- $\bigcirc$ Lung cancer

- $\bigcirc$ Malaria

- $\bigcirc$ hIVIAIDS

After the initiation of TB surveillance in 1953, TB case rates in the US steadily declined until 1985 when case rates began to climb. What were the causes of this TB resurgence? $* 1$. Better reporting of TB cases by health departments 2. HIV epidemic 3. Immigration from TB endemic countries 4. Spread of TB in high risk settings (e.g. homeless shelters) 5 . Inadequate funding for TB control and public health

- $1,2,4$ and 5 only

- 2 only

- 1 only

- 4 and 5 only

Which of the following would be the first independent nursing intervention used in working with a patient strongly suspected of having an infectious respiratory disease such as tuberculosis? *

- Open windows and doors to the room to help "air out" the room

- $\bigcirc$ Initiate antibiotic therapy with appropriate drug 
- Collect and send sputum culture to the laboratory
- $\bigcirc$ Institute airborne infection isolation precautions

The best way to ensure TB patients take their medication is to: *

- $\mathrm{O}$ Have someone watch the patient swallow each dose of medication

- $\bigcirc$ Measure serum drug levels

- $\bigcirc$ Make sure the patient understands the importance of taking the medicine

- $\bigcirc$ Ask patients if they are taking their medications

Which of the following is a special ventilation requirement for rooms that house TB patients or for labs conducting TB testing? *

- $\bigcirc$ Negative air pressure

- $\bigcirc$ Positive air pressure

- $\bigcirc$ Sterile air is vented into the areas

- $\bigcirc$ Rooms should be kept cooler than surrounding areas

Which of the following signs and symptoms best characterize a patient with latent TB infection (LTBI)? *

- $\bigcirc$ A negative TB skin test, obvious clinical symptoms and a positive sputum culture.

- $\bigcirc$ A positive TB skin test, a few clinical symptoms and a positive sputum culture.

- $\quad$ A negative TB skin test, some clinical symptoms and a normal chest $x$-ray.

- $\quad$ A positive TB skin test, no clinical symptoms and a normal chest $\mathrm{x}$-ray.

. What is the person with latent TB infection (LTBI) taught about their ability to transmit TB to another person? *

- $\bigcirc$ They should wear a mask to reduce the risk of transmitting TB infection

- $\bigcirc$ Exposed persons to TB infection should be quarantined

- $\bigcirc$ They are highly infective and isolation precautions should be instituted

- $\bigcirc$ They cannot transmit TB infection

Which of the following poses the greatest risk for latent TB to progress to active TB? *

- $\bigcirc$ Poverty and malnutrition

- $O$ Co-infection with HIV

- $\bigcirc$ Working in a laboratory 
- $\bigcirc$ Concurrent lung disease such as asthma or pneumonia

Which of the following are the most common clinical features of pulmonary TB? *

- Chills, edema, and shortness of breath

- $\bigcirc$ swollen lymph nodes, painful joints and fatigue

- $\bigcirc$ Cough, weight loss and night sweats

- $\bigcirc$ Headache, disorientation and difficulty breathing

What is the most common route of transmission of Mycobacterium tuberculosis? *

- $\bigcirc$ Eating food contaminated with M. tuberculosis bacilli

- $\bigcirc$ Drinking water contaminated with M. tuberculosis bacilli

- $\bigcirc$ Breathing in M. tuberculosis bacilli found on fomites (bed sheet, utensils, etc.)

- $\bigcirc$ Breathing in contaminated droplet nuclei generated from coughing or sneezing

In order to control the transmission of TB in hospitals, patients suspected of or known to have active pulmonary or laryngeal TB are housed in airborne infection isolation (All) rooms. One of the engineering standards for these rooms relates to air pressure. Which type of air pressure is correct for an All room? *

- Variable

- $\bigcirc$ Positive

- $\bigcirc$ Neutral

- $\bigcirc$ Negative

To obtain the latest information on TB case rates in the United States, you should locate the website of which of the following organizations? *

- $\bigcirc$ Your local health department

- Centers for Disease Control and Prevention

- $\bigcirc$ Any school of public health in your state

- United Nations

What organization should one contact to obtain the latest information on the incidence of TB internationally? *

- $\bigcirc$ Peace Corps website

- $\bigcirc$ Centers forDisease Control and Prevention (CDC) website

- $\bigcirc$ US Agency for International Development (USAID) website 
- $\bigcirc$ World Health Organization (WHO) website

A TB case diagnosed by a private physician in his/her office should be reported to: *

- $\quad$ The Centers for Disease Control and Prevention

- $\bigcirc$ The state health department

- $\bigcirc$ No one, as reporting violates patient confidentiality

- $\bigcirc$ The state medical society

The most important public health practice in the control and the interruption of transmission of tuberculosis is the: *

- $\bigcirc$ Universal tuberculin skin test (TST) or blood assay for M. tuberculosis (BAMT) evaluation of children entering school

- $\bigcirc$ Bacille Calmette-Guerin (BCG) vaccination

- $\bigcirc$ Rapid identification and initiation of treatment for all persons with active pulmonary TB

- Use of N95 respirators by health care workers

Which of the following groups is the highest priority for public health professionals in the United States who are employing targeted testing and treatment of latent TB infection (LTBI)?*

- $\bigcirc$ Children entering school for the first time

- Close contacts of active TB cases

- $\bigcirc$ Injection drug users

- $\bigcirc$ Persons immigrating to the US from high TB prevalance areas

Which of the following two signs and symptoms are characteristic of pulmonary TB but not typical of community-acquired pneumonia? *

- $\bigcirc$ Cough and fever

- Weight loss and night sweats

- $\bigcirc$ Fever and chills

- $\bigcirc$ Cough and sputum production

Which of the following is the most applicable nursing assessment for a patient with newly diagnosed active TB disease who states "I can protect my family from tuberculosis by not touching any of them."? *

- Disturbed thought processes related to isolation

- $\bigcirc$ Altered protection related to impaired stress response 
- $\bigcirc$ Risk for disease transmission related to lack of knowledge

- $\bigcirc$ Ineffective denial related to increased anxiety

Mr. James, a homeless patient diagnosed with active TB disease states "I feel so alone and rejected by my friends." Of the following, which is most appropriate nursing diagnosis for this patient? *

- $\bigcirc$ Risk of powerlessness

- $O$ Impaired adjustment

- $O$ Risk for loneliness

- $\bigcirc$ Social isolation

Name $*$

Please share any comments you have about the study, the case studies or TB in general. Your input is greatly appreciated!

\section{Submit}

